\title{
Synaptic Plasticity in Morphologically Identified CA1 Stratum Radiatum Interneurons and Giant Projection Cells
}

\author{
Brian R. Christie, ${ }^{1 *}$ Kevin M. Franks, ${ }^{2}$ \\ Jeremy K. Seamans, ${ }^{2}$ Karin Saga, ${ }^{2}$ \\ and Terrence J. Sejnowski ${ }^{2,3}$
}

\section{${ }^{1}$ University of South Dakota School of Medicine, Vermillion, South Dakota}

\author{
${ }^{2}$ Computational Neurobiology Laboratory, Howard \\ Hughes Medical Institute, Salk Institute for Biological \\ Studies, La Jolla, California
${ }^{3}$ Department of Biology, University of California at San Diego, La Jolla, California

\begin{abstract}
Long-term potentiation (LTP) of synaptic efficacy was examined in interneurons and giant cells in the stratum radiatum region of the hippocampal CA1 subfield. Cells were visually selected using differential interference contrast (DIC) optics and filled with biocytin while being recorded using whole-cell patch-clamp techniques. Electrophysiological criteria, including spike height, width, and degree of spike adaptation shown to sustained depolarization, proved inadequate for differentiating interneurons from giant cells. We found that cells in the stratum radiatum, however, could be reliably differentiated using DIC optics or following intracellular staining. The response of the two cell types to tetanic stimulation further dissociated them. Long-term potentiation, dependent on the activation of NMDAr ( Nmethyl-D-aspartate receptors), could reliably be induced in interneurons with stimuli administered at $200 \mathrm{~Hz}$, but not $100 \mathrm{~Hz}$. Giant cells, in contrast, exhibited NMDA receptor-dependent LTP in response to $100-\mathrm{Hz}$ stimuli, but not the $200-\mathrm{Hz}$ stimuli. LTP induction in interneurons also appeared temperature-dependent, being much more robust at $34^{\circ} \mathrm{C}$ than at room temperature. The LTP in both cell types required postsynaptic calcium influx, and was not due to the passive propagation of LTP induction in neighboring pyramidal cells. These results suggest that different cell types within the hippocampal formation may preferentially alter synaptic connectivity in a frequencyspecific manner. Hippocampus 2000;10:673-683. ๑ 2000 Wiley-Liss, Inc.
\end{abstract}

KEY WORDS: $\quad$ LTP; LTD; calcium; NMDA; hippocampus

\section{INTRODUCTION}

Long-term potentiation of synaptic efficacy is a leading candidate mechanism for learning and memory processes. In numerous studies, LTP has

Grant Sponsor: HHMI; Grant number: 528012.

*Correspondence to: Brian R. Christie, Ph.D., University of South Dakota School of Medicine, 414 East Clark Street, Vermillion, SD 57069.

E-mail: bchristi@usd.edu

Accepted for publication 19 April 2000 been reliably induced at the asymmetric spines formed onto hippocampal principal cells, i.e., the excitatory projection neurons of the hippocampal formation. The induction of LTP at synapses onto the inhibitory neurons of the hippocampal formation is more controversial (reviewed in Freund and Buzsaki, 1996; McBain et al., 1999). LTP-inducing conditioning stimulation $(100 \mathrm{~Hz}$, 1 s) has been reported to produce LTP (Buzsaki and Eidelberg, 1981; Taube and Schwartzkroin, 1987; Stelzer et al., 1994; Cowan et al., 1998), long-term depression (McMahon and Kauer, 1997), or no change (Maccaferri and McBain, 1996) in stratum radiatum interneurons. These same stimuli have been shown to produce LTP in stratum oriens interneurons, but not in interneurons located near the border of the stratum radiatum and stratum moleculare (Ouardouz and Lacaille, 1995).

A critical concern for elucidating LTP in interneurons is their morphological identification. It was recently shown that a population of projection cells, known as giant cells, exists in the stratum radiatum region of the hippocampal formation (Gulyas et al., 1998). Giant cells exhibited an NMDAr-dependent form of LTP when depolarized to $-20 \mathrm{mV}$ and synaptically stimulated at $1 \mathrm{~Hz}$ (Maccaferri and McBain, 1996; Gulyas et al., 1998), whereas identified interneurons did not (Maccaferri and McBain, 1996). In many studies it is unclear whether interneurons or projection cells were being studied, and histological identification may be critical for differentiating these cells to determine their capacity to exhibit LTP.

There are also a number of molecular and structural differences between interneurons and principal cells 
that suggest that the rules for the induction of synaptic plasticity may differ for the two cell types. Both principal cells and interneurons have NMDA receptors and voltage-gated $\mathrm{Ca}^{2+}$ channels; however, interneurons appear to lack both CaMKII $\alpha$ and calcineurin (Sik et al., 1998). Once thought integral for LTP expression, it is now clear that activation of CaMKII $\alpha$ and calcineurin by calcium entry through the NMDAr receptor is not essential for NMDAr-dependent LTP (Wang and Kelly, 1996; Hinds et al., 1998). A second difference is that, compared to principal cells, interneurons are relatively devoid of spines (Amaral and Witter, 1989; Van Groen and Wyss, 1990; Sik et al., 1998; Gulyas et al., 1998), and interneuron synaptic plasticity does not appear to be synapse-specific (McMahon and Kauer, 1997; Cowan et al., 1998). The possibility that interneurons may express a form of LTP that is not dependent on NMDAr activation has not been explored, and the only stimulus paradigms that have been used are ones that reliably induce NMDAr-dependent LTP and LTD in principal cells. The present experiments compare the effects of different forms of tetanic stimulation in morphologically identified interneurons and giant cells located in the stratum radiatum layer of the hippocampal CA1 subfield to address some of these issues.

\section{MATERIALS AND METHODS}

\section{Slice Preparation}

Hippocampal slices $(350-400 \mu \mathrm{m})$ were prepared on a Vibratome (Oxford series 1000) from Sprague-Dawley rats (postnatal days 14-35). Slices were dissected in a chilled medium ( $\mathrm{pH} 7.4$ ) containing (in $\mathrm{mM}) 110.0$ choline chloride, $2.5 \mathrm{KCl}$, $1.25 \mathrm{NaH}_{2} \mathrm{PO}_{4}, 25.0 \mathrm{NaHCO}_{3}, 0.5 \mathrm{CaCl}_{2}, 7.0 \mathrm{MgCl}_{2}, 25.0$ dextrose, 1.3 ascorbate, and 2.4 pyruvate, continuously bubbled with $95 \% \mathrm{O}_{2} / 5 \% \mathrm{CO}_{2}$. To maximize the number of CA1 neurons that extend their dendritic trees in the same plane as the slice, the brains were placed on their temporal poles, and oriented at an angle of $25-30^{\circ}$ for sectioning. Cut slices were then incubated at $32^{\circ} \mathrm{C}$ in artificial cerebrospinal fluid (ACSF; $\mathrm{pH}$ 7.4), continuously bubbled with $95 \% \mathrm{O}_{2} / 5 \% \mathrm{CO}_{2}$, and composed of (in mM): $125.0 \mathrm{NaCl}, 2.5 \mathrm{KCl}, 1.25 \mathrm{NaH}_{2} \mathrm{PO}_{4}$, $25.0 \mathrm{NaHCO}_{3}, 2.0 \mathrm{CaCl}_{2}, 1.3 \mathrm{MgCl}_{2}$, and 10.0 dextrose, for at least 20 minutes.

\section{Electrophysiological Methods}

Slices were stored in a circulating perfusion chamber and maintained at room temperature for a maximum of $6 \mathrm{~h}$. Individual slices were transferred to the recording chamber as required, and experiments were performed in ACSF (see above) maintained at either $23^{\circ} \mathrm{C}$ or $34^{\circ} \mathrm{C}$. Individual neurons were examined using a $60 \times$ Olympus water immersion objective and DIC optics (Christie et al., 1996). Whole-cell recording pipettes (5-7 M 2 ) were pulled from borosilicate glass (VWR Scientific) and filled with (in $\mathrm{mM}$ ): $140.0 \mathrm{KmeSO}_{4}$, 10.0 HEPES, $4.0 \mathrm{NaCl}, 0.1$ EGTA, 4.0 TrisATP, 0.3 Tris-GTP, and 14.0 phosphocreatine ( $\mathrm{pH} 7.4, \mathrm{KOH})$. Biocytin (0.2-0.4\%) was routinely added to the internal solution to allow for subsequent histological analysis. Input resistance was $200-500 \mathrm{M} \Omega$ in interneurons and $100-300 \mathrm{M} \Omega$ in giant cells. Cells were periodically monitored to ensure that series resistance did not change over the course of an experiment. Series resistance was always less than $40 \mathrm{M} \Omega$ in both cell types. Cells located in the upper half of the stratum radiatum region of the CA1 hippocampal subfield were specifically targeted for this study. Once a cell was selected, a small ( $\sim 5-\mu \mathrm{m}$ tip) bipolar stimulating electrode was placed in the distal third of the stratum radiatum, approximately $150-500 \mu \mathrm{m}$ lateral to the soma. A tight seal $(>1 \mathrm{G} \Omega)$ was initially formed, and then whole-cell recordings were made by briefly applying negative pressure to rupture the cell membrane in the electrode tip. The amplifier (Axoclamp-2B) was then immediately switched from voltage-clamp to current-clamp mode, and the resting membrane potential of the neuron was recorded. Data were filtered at $2 \mathrm{kHz}$ and digitized at $5-10 \mathrm{kHz}$, using an A/D interface (National Instruments) and analyzed using custom written software (Lee Campbell). Stimulus strengths were adjusted to $30 \%$ of that required to illicit a maximal EPSP.

\section{Stimulation Protocols}

Stimulus isolation units (Getting Instruments) provided constant current stimulation (110 $\mu$ s duration, 15-200 $\mu \mathrm{A}$ intensity) via the stimulating electrode (A-M Systems) located in the stratum radiatum, as described above. Stimuli were applied every $15 \mathrm{~s}(0.25 \mathrm{~Hz})$ to assess basal synaptic transmission. For LTP induction, a total of 200 pulses was administered at either $100 \mathrm{~Hz}$ or $200 \mathrm{~Hz}$. Stimuli were presented as 4 trains of 50 pulses, $100-\mathrm{Hz}$ and $200-\mathrm{Hz}$ stimuli as 2 trains of 100 pulses. In all experiments, excitatory postsynaptic potential (EPSP) data are expressed as a percentage relative to the initial 10-min baseline period. All statistical data were computed as an average of 20 responses per slice over a 5 -min period $25-30 \mathrm{~min}$ postconditioning, except where otherwise noted. Data are expressed at mean \pm SEM.

\section{Histology}

Slices were fixed immediately after electrophysiological recording in $4 \%$ paraformaldehyde and refrigerated for at least $24 \mathrm{~h}$. Following several washes in phosphate-buffered saline (PBS), the sections were then washed in PBS containing 10\% methanol and $1 \%$ hydrogen peroxide. Biocytin-injected cells were then visualized, using an avidin-biotinylated horseradish peroxidase (HRP) complex reaction (Vectastain ABC kit, Vector Labs) and precipitated with hydrogen peroxide in diamino benzidene. The reaction was intensified with a solution containing nickel ammonium sulfate $(1 \%)$ and cobalt chloride (1\%). The slices were then mounted on gelatin-coated slides, dehydrated, and coverslipped for post hoc microscopic analysis. 


\section{RESULTS}

\section{Identification of Stratum Radiatum Cell Types: Morphology}

The identification of the different cell types was a major concern for this series of experiments. Figure 1 shows examples of both a bipolar interneuron and a giant cell using DIC optics. Note how prominent the thick bifurcating apical dendrites of the giant cell are, while little or no dendritic process is evident around the smooth spherical surface of the interneuron soma. During the course of experimentation, we found that the shape of the soma, as well as an absence of discernible dendritic processes (especially the thick bifurcating dendrite that typifies giant cells), were the best indicators for classifying cells as interneurons using DIC optics. In most cases, interneuron somata appeared as round or ovoid spheres. Conversely, the larger pyramidal-shaped soma and thick bifurcating dendrite have become our main criteria for identification of giant cells in the upper stratum radiatum region with DIC optics.

Cells were filled with biocytin $(0.2-0.4 \%)$ so that they could be morphologically identified using light microscopy. Figure 1C,D shows the distinct morphologies of the somata and main dendrites arising from interneurons and giant cells in the stratum radiatum. Note how two main dendrites extend in the apical direction away from the soma of the giant cell in the right, while in the interneuron, numerous smaller dendritic processes extend laterally in both directions. As depicted in Figure 1E,F, interneurons and giant cells could be further differentiated by the absence or presence of spiny processes on the dendrites (Gulyas et al., 1998; Parra et al., 1998). In the present experiments, all cells classified as interneurons were relatively devoid of dendritic spines. These results are in agreement with works that morphologically described stratum radiatum neurons (Lacaille and Schwartzkroin, 1988; McBain and Dingledine, 1993; Valtschanoff et al., 1993; Williams et al., 1994; Maccaferri and McBain, 1996; Gulyas et al., 1998). Our results indicate that post hoc histological analysis is an extremely useful, but not essential, means to establish neuronal identity. The DIC optics used in the present study provides an equally reliable means to differentiate giant cells from interneurons in living tissue. Figure 2 presents some examples of the cell types examined in the present work. A key feature for this study is that all of the cell bodies and the majority of dendrites of each cell were confined mainly to the stratum radiatum of the hippocampal CA1 subfield.

\section{Identification of Stratum Radiatum Cell Types: Electrophysiology}

A commonly used method for distinguishing interneurons from principal cells electrophysiologically is to examine neuronal responses to depolarizing current injections. Interneurons are identified in this manner as those cells that 1 ) exhibit trains of nonaccommodating action potentials in response to depolarizing current injection, and/or 2) have short-duration action potentials which are followed by a deep fast afterhyperpolarizing potential (fAHP) (Schwartzkroin and Mathers, 1978; Lacaille et al., 1989; Buhl et al., 1995; Cowan et al., 1998).
In the present study, the only prominent feature of the electrophysiological profile of interneurons that was not commonly observed in giant cells was the presence of a pronounced fAHP (Fig. 3). Attempts to dissociate the two cell types on the basis of spike width and amplitude were inconclusive. While giant cells typically had broader and larger amplitude action potentials than interneurons, it was often the case that both cell types had action potentials of equivalent duration and amplitude (Fig. $3 \mathrm{~A}, \mathrm{~B})$. Similarly, both identified giant cells, and interneurons exhibited a wide range of firing patterns in response to depolarizing current injections. Giant cells commonly exhibited some degree of spike frequency accommodation (Fig. 3C,D). However, adaptation was not observed in all cells (Fig. 3E). The interneurons recorded in this study displayed a regular firing pattern for the most part (Fig. 3I,J), although some cells exhibited burst firing (Fig. $3 \mathrm{H}$ ) or were strongly accommodating (Fig. 3G) to the same stimuli. These findings are similar to those for anatomically identified basket and bistratified cells in the hippocampus (Buhl et al., 1996). These results indicate that it is difficult to dissociate stratum radiatum giant cells from interneurons on the basis of their firing characteristics alone.

\section{Stimulation $(200 \mathrm{~Hz})$ Induces LTP in Interneurons But Not Giant Cells}

LTP induction was attempted at both $23^{\circ} \mathrm{C}$ (room temperature) and $34^{\circ} \mathrm{C}$. As show in Figure 4, the stimuli administered to interneurons at $200 \mathrm{~Hz}$ were ineffective at inducing LTP at room temperature $\left(30 \pm 13 \%\right.$ t $\left._{(9)}=-2.19, P=0.051\right)$, while LTP was reliably induced by these same stimuli at $34^{\circ} \mathrm{C}\left(91 \pm 29 \%\right.$; $\mathrm{t}_{(9)}=$ $3.1, P<0.05)$. At $23^{\circ} \mathrm{C}$ only $6 / 10$ cells exhibited LTP greater than $20 \%$, while 3 cells exhibited $<20 \%$ change, and one cell exhibited $>20 \%$ LTD. With the perfusion maintained at $34^{\circ} \mathrm{C}$, LTP $(>20 \%)$ was observed in $8 / 10$ neurons. One neuron in this group exhibited $>20 \%$ LTD. A direct comparison of the two groups revealed that cells tested at $34^{\circ} \mathrm{C}$ showed a significantly greater long-lasting LTP than that exhibited by those tested at $23^{\circ} \mathrm{C}$ $\left(\mathrm{t}_{(9)}=2.6, P<0.05\right)$.

Stratum radiatum giant cells tested at $23^{\circ} \mathrm{C}$, like interneurons, failed to exhibit a significant degree of long-lasting LTP $(5 \pm 8 \%, \mathrm{n}=6 ; P>0.05 ;$ Fig. 4$)$. Only one cell showed $>20 \%$ LTP, one showed smaller LTP, and the remaining four did not exhibit any degree of plasticity. LTP was not larger at $34^{\circ} \mathrm{C}$ in giant cells $(19 \pm 13 \%, \mathrm{n}=12 ; P>0.05)$. Six cells did not exhibit any change in synaptic efficacy, while 5/12 exhibited LTP $(>20 \%)$ and one exhibited LTD (>20\%). There was no significant difference in degree of plasticity observed between the two cell types at $23^{\circ} \mathrm{C}$. However, interneurons showed significantly greater LTP than giant cells when tested at $34^{\circ} \mathrm{C}$ $\left(\mathrm{t}_{(20)}=2.359, P<0.05\right)$.

\section{Conditioning Stimulation $(100 \mathrm{~Hz})$ Induces LTP in Giant Cells But Not Interneurons}

Given the previous results, all subsequent experiments were performed at $34^{\circ} \mathrm{C}$. As shown in Figure 6, synaptic efficacy was increased markedly in giant cells $\left(51 \pm 18 \%, \mathrm{t}_{(10)}=2.8, P<0.05\right)$. Individually, $6 / 11$ cells exhibited LTP $>20 \%$, while alterations in 

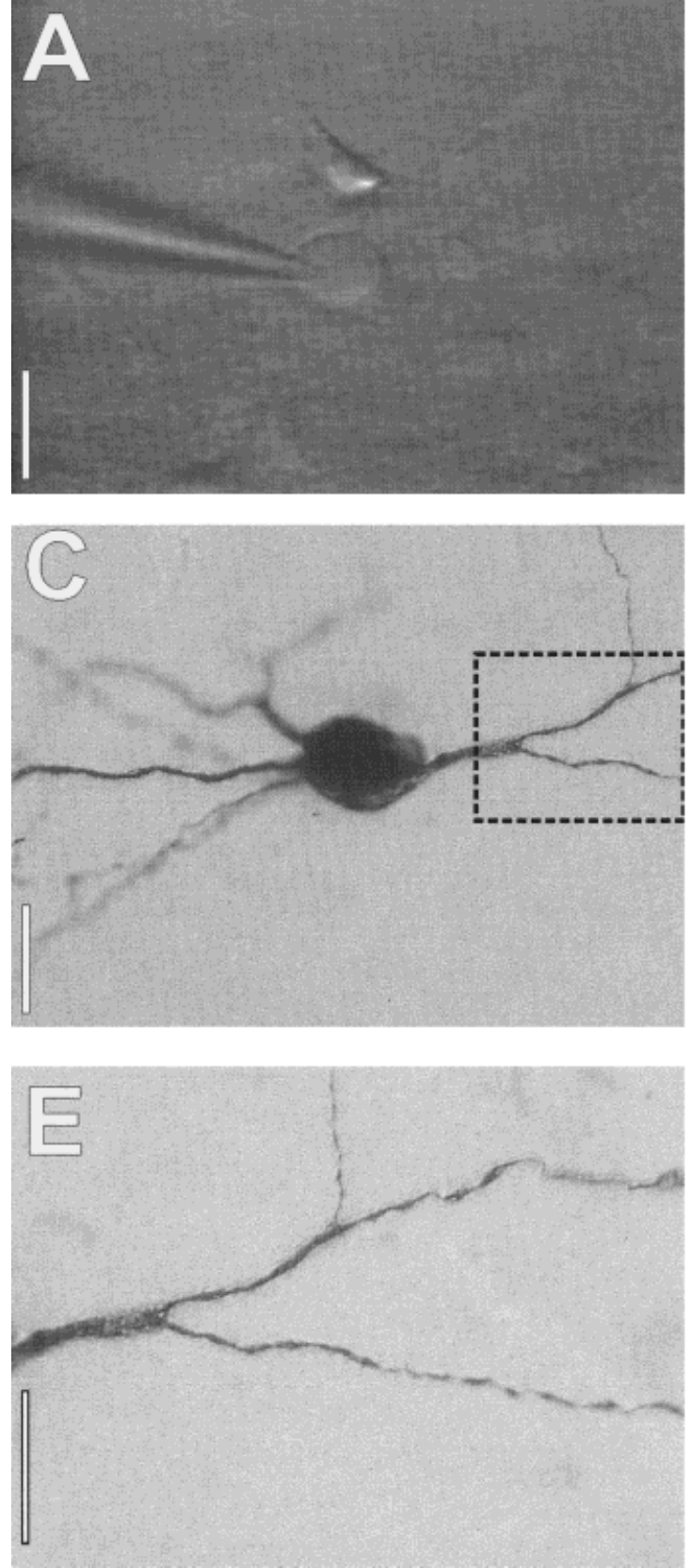

FIGURE 1. Anatomical characterization of interneurons and giant cells in the hippocampal CA1 subfield stratum radiatum. A,B: Differential interference contrast (DIC) photomicrographs of wholecell pipettes attached to cell bodies in the CA1 stratum radiatum, taken with a $60 \times$ water immersion lens. The large bifurcating apical dendrites of giant cells were easily viewed under these conditions (B); the dendrites of interneurons were much more difficult to distinguish (A). C,D: Photomicrographs of the cells depicted in A and B, following the expression of biocytin. Dendrites are now discernible, extend-

synaptic efficacy in the remaining cells were $<20 \%$. No cells exhibited LTD. In contrast to the giant cells, radiatum interneurons showed smaller increases in synaptic efficacy on average (26 \pm $14 \%, \mathrm{n}=12 ; P>0.05)$. Five cells exhibited $>20 \%$ in synaptic efficacy, while six showed $>20 \%$ change, and the remaining cell exhibited LTD $>20 \%$.
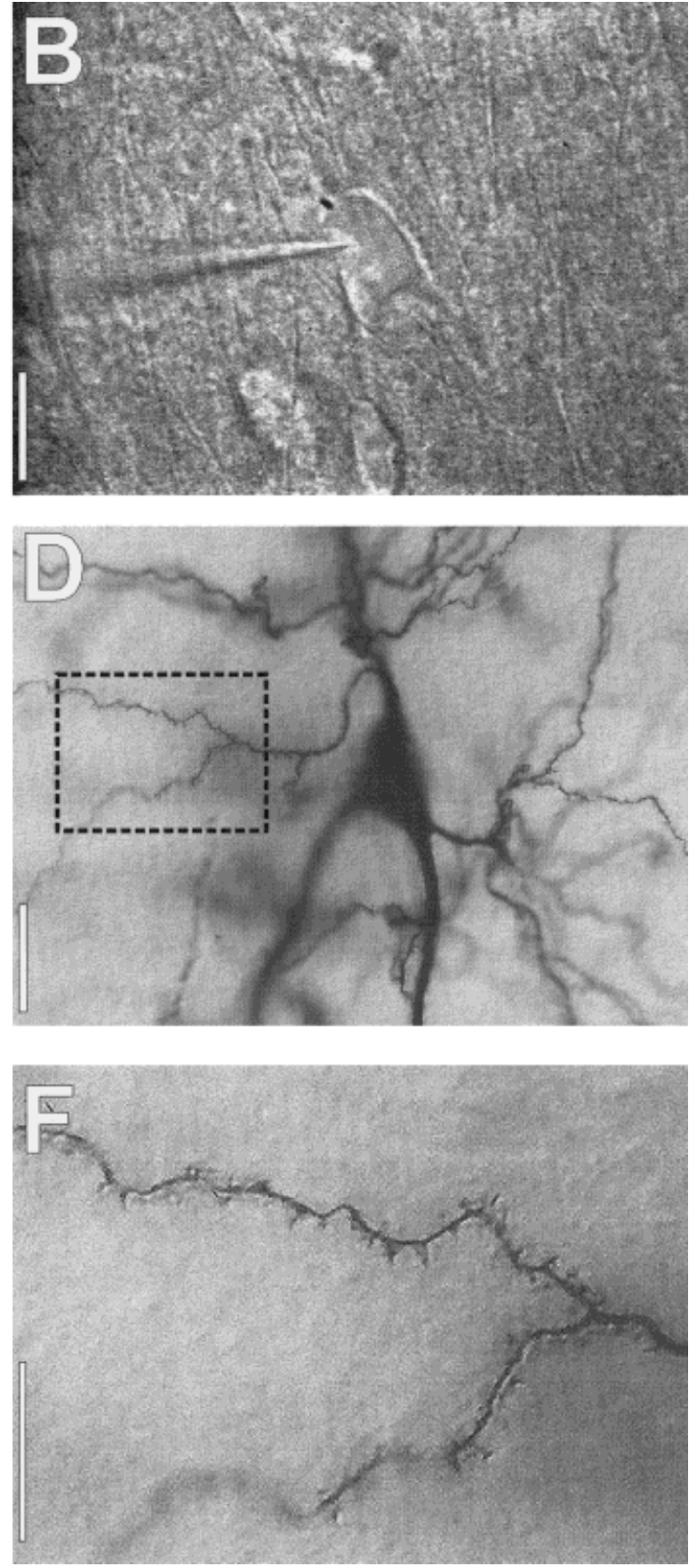

ing laterally in both directions in the interneuron (C), while a number of secondary dendrites are now also visible coming off the two main apical dendrites and the basal portion of the soma of the giant cell (D). Dotted areas indicate the regions enlarged and shown in E and F. E,F: Like pyramidal cells, the second-order dendrites of giant cells are covered in spines, while both the main and second-order dendrites of the interneurons examined in the present study appear aspiny. The CA1 pyramidal cell layer is located at the top of all photomicrographs, out of the field of view. Scale bars $=25 \mu \mathrm{m}$.

\section{LTP Induction in Hippocampal Giant Cells and Interneurons Is Calcium-Dependent and Not Passively Propagated}

Research into the mechanisms responsible for the induction of LTP suggests that an increase in postsynaptic $\mathrm{Ca}^{2+}$ plays an important role 


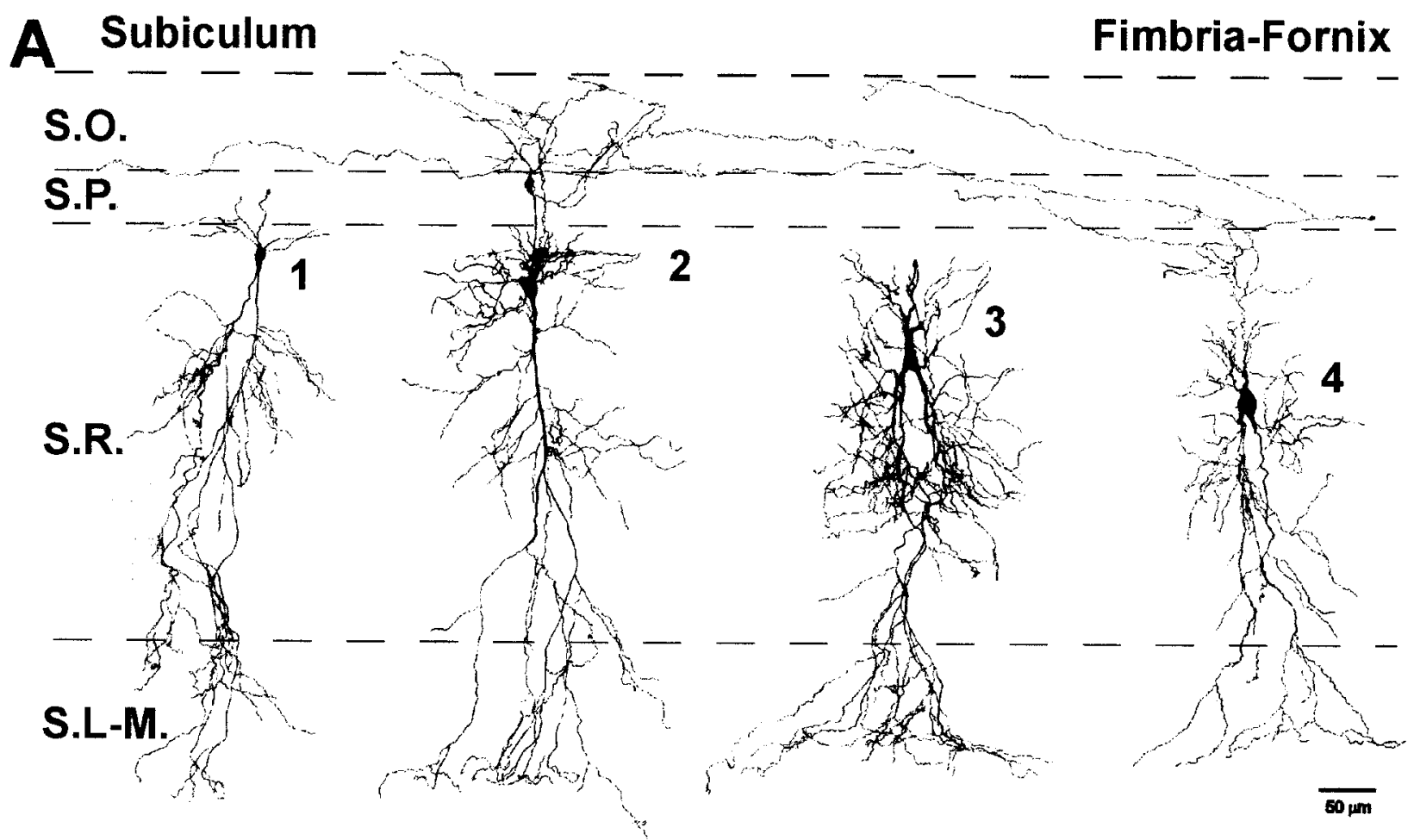

B

S.O.

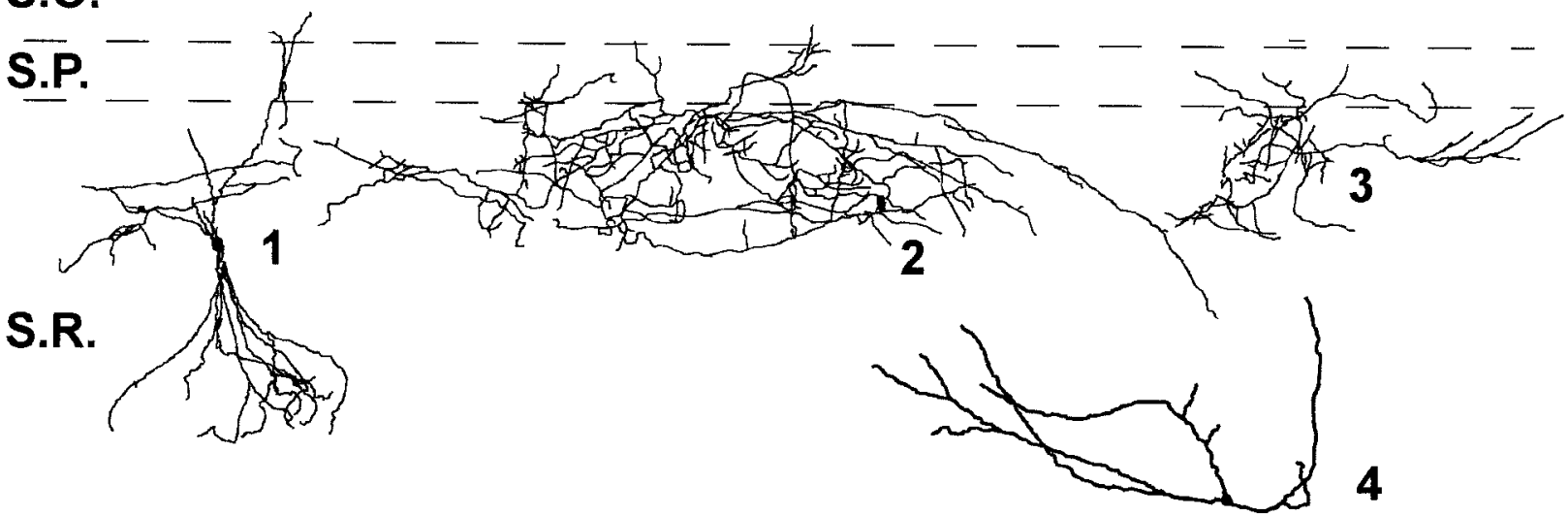

S.L-M.

FIGURE 2. Camera lucida tracings of representative giant cells and nonpyramidal cell types recorded from in the present study. A: All giant cells recorded in the present study exhibited a stereotypic somatic and dendritic morphology. The large soma was always located in the upper half of the stratum radiatum (S.R.), and dendritic processes always descended into the stratum lacunosum-moleculare (S.L.-M.). Typically the dendritic processes bifurcated at the level of the soma $(1,3,4)$; however, in a few cells $(2)$, the bifurcation occurred 50-100 $\mu \mathrm{m}$ from the soma. These cells more closely resembled pyramidal cells; however, they invariably gave rise to axonal process that bifurcated at the level of the stratum oriens (S.O.), extending away towards both the fimbria-fornix and the subiculum. In many cases, numerous axon collaterals could be seen localized to the stratum pyrimidale (S.P.) and/or S.O. layers $(1,2,4)$. B: Interneurons, on the whole, tended to be a more morphologically heterogeneous population of cells, with smaller somata than those of giant cells. The main common feature of these cells was that the majority of their dendritic processes were confined to the S.R. region. Many cells exhibited a bipolar appearance, with numerous small dendrites extending away both apically and basally (1). Dense axonal processes (not shown) extended into the S.P. and S.O. from many of these cells. Cells with similar somatic morphology to 1 could also extend numerous dendritic processes laterally across the S.R. $(2,3)$. These cells tended to localize their axonal processes around the S.P. region. A few recordings were also obtained from cells located closer to the S.L.-M. (4). These cells had numerous small dendritic processes extending laterally across the S.R. Axonal processes in these cells were mainly localized to the S.R. and S.P. layers. 
A

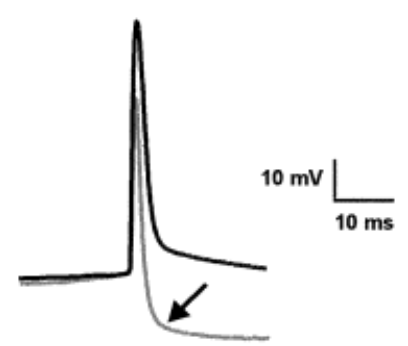

\section{C - F Giant Cells}
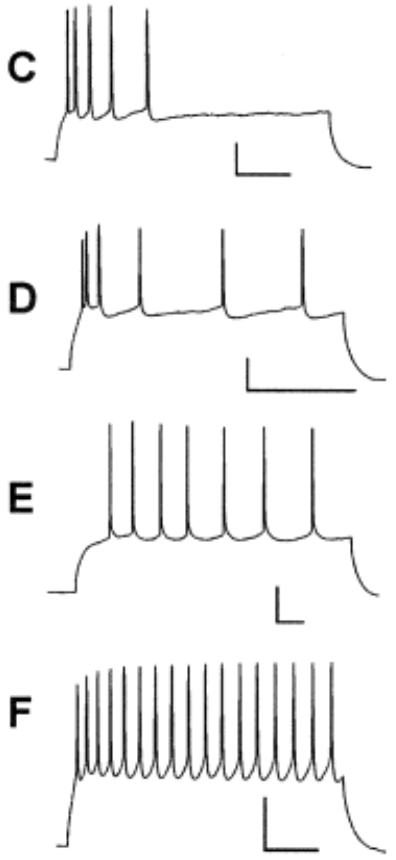

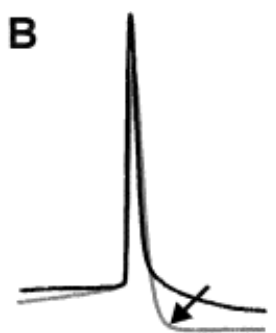

\section{G - J Interneurons}

G

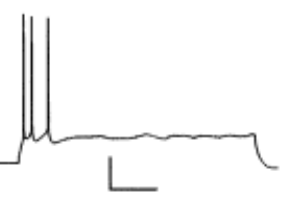

H
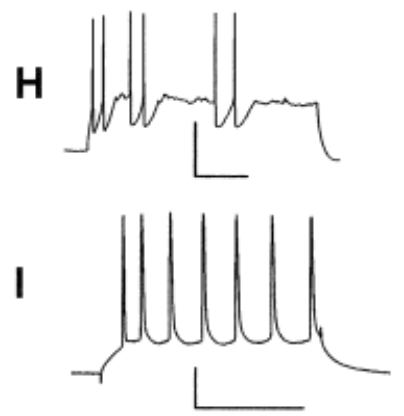

$J$

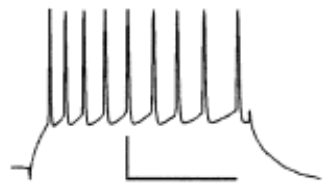

FIGURE 3. Interneurons were differentiated from some giant cells by the presence of a large fast afterhyperpolarizing potential (fAHP). A: Example of an action potential recorded from an interneuron (gray) compared with one recorded from a giant cell (black). Note the pronounced AHP observed in the interneuron but not the giant cell (arrow). In most cases, interneuron APs were also shorter in duration, and smaller in amplitude than those recorded from giant cells. B: Example of how AP amplitude and duration were not always reliable indicators of cell type. The interneuron AP shown here (gray) could be differentiated from the giant cell AP by the presence of a pronounced fAHP (arrow). C-F: In response to a sustained depolarizing current injection, giant cells typically responded with some degree of spike frequency adaptation (C,D). In some giant cells, however, little or no spike frequency adaptation was apparent in morphologically identified giant cells (E,F). Interneurons, in contrast, typically responded to depolarizing current injection with little or no spike frequency adaptation (I,J). Some morphologically identified interneurons also displayed strong spike frequency adaptation $(G)$, while in others, the depolarizing stimulus elicited bursts of action potentials (H). Scale bars, C-J: $20 \mathrm{mV} ; 100 \mathrm{~ms}$.

in the induction phase of both LTD and LTP (reviewed in Bear and Malenka, 1994; Christie et al., 1994; Larkman and Jack, 1995). The depolarization would be expected to be sufficient to open VGCCs and/or NMDA receptors, allowing calcium entry into the postsynaptic cell. To determine whether the LTP induced in these cells was a

calcium-dependent process specific to the postsynaptic cell, we included the calcium chelator EGTA $(10 \mathrm{mM})$ in the whole-cell pipette to severely attenuate postsynaptic calcium levels (Lynch et al., 1983; Malenka et al., 1988; Yeckel et al., 1999). Neither morphologically identified interneurons nor giant cells exhibited LTP under these conditions (Fig. 6). Giant cells exhibited a modest depression $(-12 \pm 18$, $\mathrm{n}=5, P>0.05$ ), with only $1 / 5$ cells showing a change in synaptic efficacy greater than $20 \%$. No interneuron tested exhibited a significant change in the slope of EPSPs recorded following the application of the tetanus under these conditions $(7 \pm 3 \%, \mathrm{n}=5, P>0.05)$. These experiments provide evidence against the possibility that the LTP observed in giant cells and interneurons was being passively propagated from pyramidal cells (Maccaferri and McBain, 1995). Since LTP was blocked under these conditions, it is unlikely that the previous results reflect pyramidal cell LTP being expressed disynaptically.

\section{Role of NMDAr in Stratum Radiatum Neuronal Synaptic Plasticity}

We next attempted to ascertain the mechanisms involved in LTP genesis in interneurons and giant cells. Although the LTP induced in pyramidal cells with $200-\mathrm{Hz}$ stimulation consists of both an NMDAr-mediated component and a VGCC-mediated component (Grover and Teyler, 1990a; Grover, 1998), the contribution of the NMDAr appears greater in young animals like those used in this study (Shankar et al., 1998). We found that both hippocampal stratum radiatum interneurons and giant cells exhibited NMDAr-mediated responses when DNQX $(20 \mu \mathrm{M})$ and Bicuculline $(2 \mu \mathrm{M})$ were added to the ACSF (data not shown).

To examine the role of NMDA-receptor activation in stratum radiatum neuronal LTP, whole-cell recordings were made in the presence of the NMDA-receptor antagonist DL-APV (DL-2-amino-5-phosphonovaleric acid). As shown in Figure 7, the $200-\mathrm{Hz}$ conditioning stimulation did not induce LTP in interneurons when APV was present $\left(0.1 \pm 6 \% ; \mathrm{n}=6 ; \mathrm{t}_{(5)}=0.7, P>0.05\right)$. Individually, LTP $(>20 \%)$ was observed in only one cell; LTD $(>20 \%)$ was apparent in another; and the remaining four cells did not exhibit any significant changes.

In giant cells, LTP was preferentially induced by the $100-\mathrm{Hz}$ stimuli in the previous experiments. However the addition of APV prevented the induction of LTP in giant cells $(13 \pm 16 \%, n=6)$. In some cells, we attempted to induce LTP following APV exposure. However, even following a 30-min washout in normal ACSF, we were unable to induce LTP in either cell type. Given the long time course of these experiments, this may reflect a washout of some critical intracellular component that is essential for LTP induction in these cells.

We also examined the effects of NMDAr blockade in giant cells to see if we could elicit an NMDAr-independent form of LTP with the $200-\mathrm{Hz}$ conditioning stimuli, similar to that observed in pyramidal cells (Grover and Teyler, 1990a, 1995; Grover, 1998). Surprisingly, a long-lasting form of LTD developed in these cells rather than the expected LTP $\left(-34 \pm 9 \%, \mathrm{n}=7 ; \mathrm{t}_{(6)}=3.7, P<\right.$ $0.05)$. This finding, along with the failure of the $200-\mathrm{Hz}$ stimuli to generate LTP in control conditions, clearly differentiates giant cells from pyramidal neurons (Fig. 8). 


\section{Interneurons}

A1 $23^{\circ} \mathrm{C}$
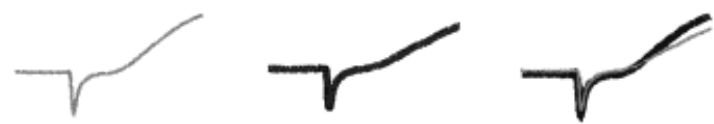

A2 $34^{\circ} \mathrm{C}$
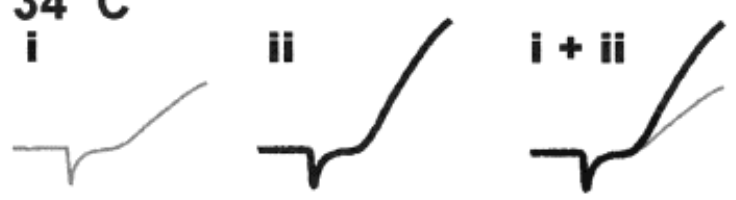

C

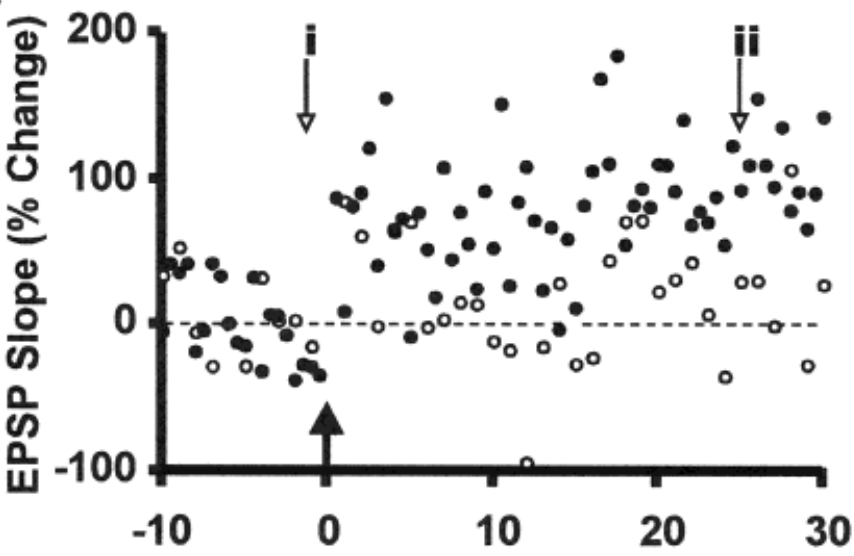

E

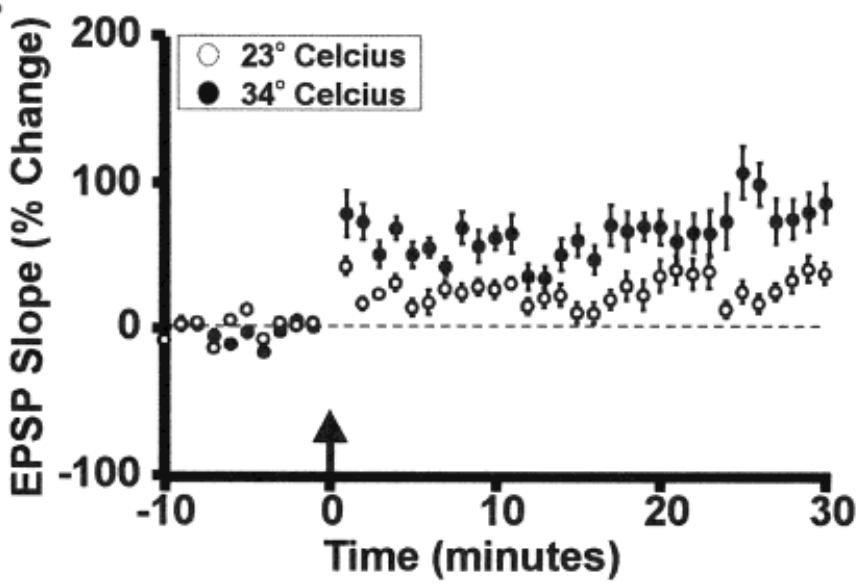

FIGURE 4. Temperature- and frequency-specific synaptic plasticity in stratum radiatum interneurons and giant cells. A,B: Averaged evoked responses recorded from morphologically identified interneurons $(\mathrm{A})$ and giant cells $(\mathrm{B})$ prior to (gray) and following (black) the application of $200-\mathrm{Hz}$ tetanic stimulation at either $23^{\circ} \mathrm{C}(\mathrm{A1}, \mathrm{B} 1)$ or $34^{\circ} \mathrm{C}(\mathrm{A} 2, \mathrm{~B} 2)$. C: Individual responses recorded from interneurons administered the $200-\mathrm{Hz}$ conditioning stimuli at either $23^{\circ} \mathrm{C}$ (open circles) or $34^{\circ} \mathrm{C}$ (solid circles). D: Individual responses recorded from

\section{Giant Cells}

B1 $23{ }^{\circ} \mathrm{C}$

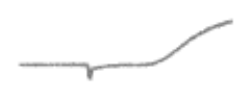

ii $\quad$ i + ii



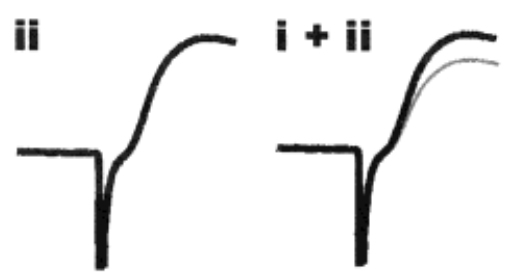



$\mathbf{F}$

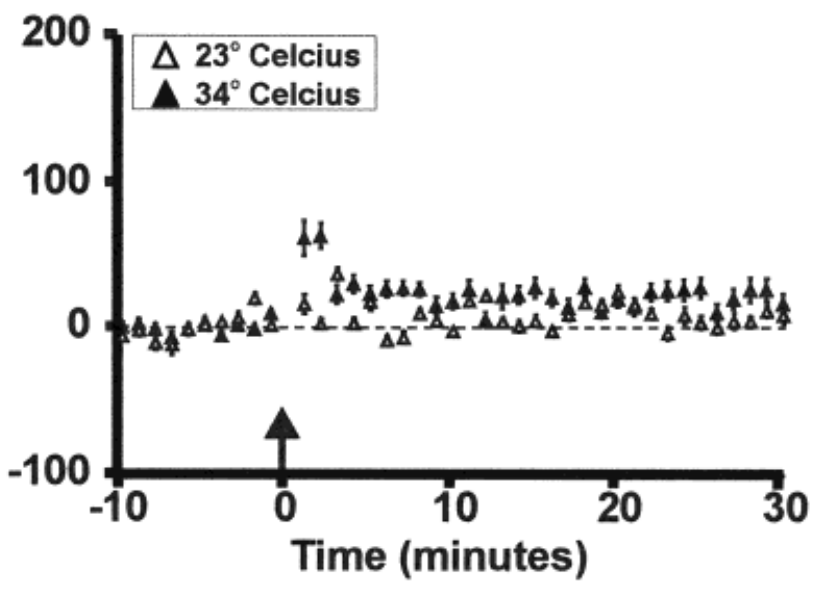

giant cells administered the $200-\mathrm{Hz}$ conditioning stimuli at either $23^{\circ} \mathrm{C}$ (open triangles) or $34^{\circ} \mathrm{C}$ (solid triangles). E,F: Averaged group responses for all interneurons $(\mathrm{E})$ and giant cells $(\mathrm{F})$ receiving the $\mathbf{2 0 0}-\mathrm{Hz}$ conditioning stimulation at the two temperatures. A significant degree of LTP was only produced in interneurons in ACSF maintained at $34^{\circ} \mathrm{C}\left(91 \pm 29 \%, n=10 ; t_{(9)}=3.1, P<0.05\right)$ and not in giant cells maintained at the same temperature $(19 \pm 13 \%, n=12$; $P>0.05)$. 


\section{Interneurons}



Giant Cells

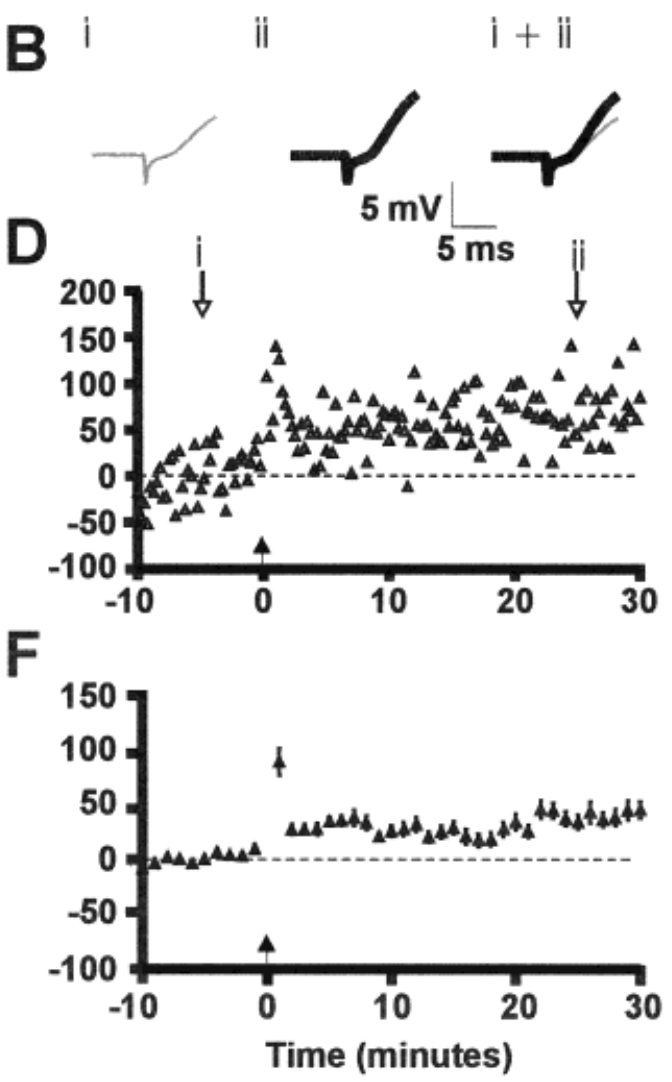

FIGURE 5. Giant cells, but not interneurons, exhibited LTP following 100-Hz conditioning stimulation. A,B: Ensemble averages of evoked responses obtained prior to (i) and following (ii) the application of the $100-\mathrm{Hz}$ stimuli in a morphologically identified interneuron (A) and giant cell (B). C,D: Percentage change in recorded synaptic EPSPs from an interneuron $(\mathrm{C})$ and a giant cell (D) prior to and

\section{DISCUSSION}

\section{Differentiating Stratum Radiatum Giant Cells From Interneurons}

The present experiments confirm previous reports that differentiate hippocampal stratum radiatum giant cells and interneurons on the basis of several morphological differences (Lacaille et al., 1989; van Groen and Wyss, 1990; Maccaferri and McBain, 1996; Gulyas et al., 1998). The large soma and bifurcating apical dendrites of giant cells were easily visible using DIC optics, and could often be followed for several hundred microns as they extended towards the stratum moleculare region. The dendrites of interneurons, in contrast, could usually not be followed for more than 50 $\mu \mathrm{m}$. Second, the somata of giant cells were typically triangular in appearance and approximately $20 \mu \mathrm{m}$ in size. The somata of the interneurons used in this study were either round or ovoid in appearance, and appeared much smaller $(10-15 \mu \mathrm{m})$ under DIC optics. Finally, the biocytin-stained interneurons used in this study following the application of the $100-\mathrm{Hz}$ stimuli. E,F: Averaged responses of all interneurons (E) administered the $100-\mathrm{Hz}$ stimuli do not exhibit a significant degree of LTP $(26 \pm 14 \%, n=12)$, while those obtained from giant cells $(\mathrm{F})$ are significantly potentiated (40 \pm $\left.16 \%, \mathrm{t}_{(9)}=2.5, P<0.05\right)$.

possessed dendritic processes whose primary and secondary branches were almost utterly devoid of visible spines. Giant cells, in contrast, possessed dendritic processes that were heavily covered in spiny processes. Gulyas et al. (1998) suggested that these morphological features indicate that giant cells are likely excitatory cells and not inhibitory. It needs to be established whether these cells are GAD-positive to determine whether these cells are excitatory or inhibitory.

Electrophysiologically, the large fAHP differentiated interneurons from giant cells, which lack a large fAHP. There were no differences in action potential height and width that could be used to reliably differentiate the cell types. Both interneurons and giant cells could respond with adapting or nonadapting trains of action potentials, though a small population of interneurons also responded with bursts of action potentials (see also Lacaille et al., 1988; Williams et al., 1994). This variability in the responsiveness of these cells makes it difficult to differentiate between them on the basis of electrophysiological criteria alone, and we were only fully confident of a cell's classification when confirmed visually. 

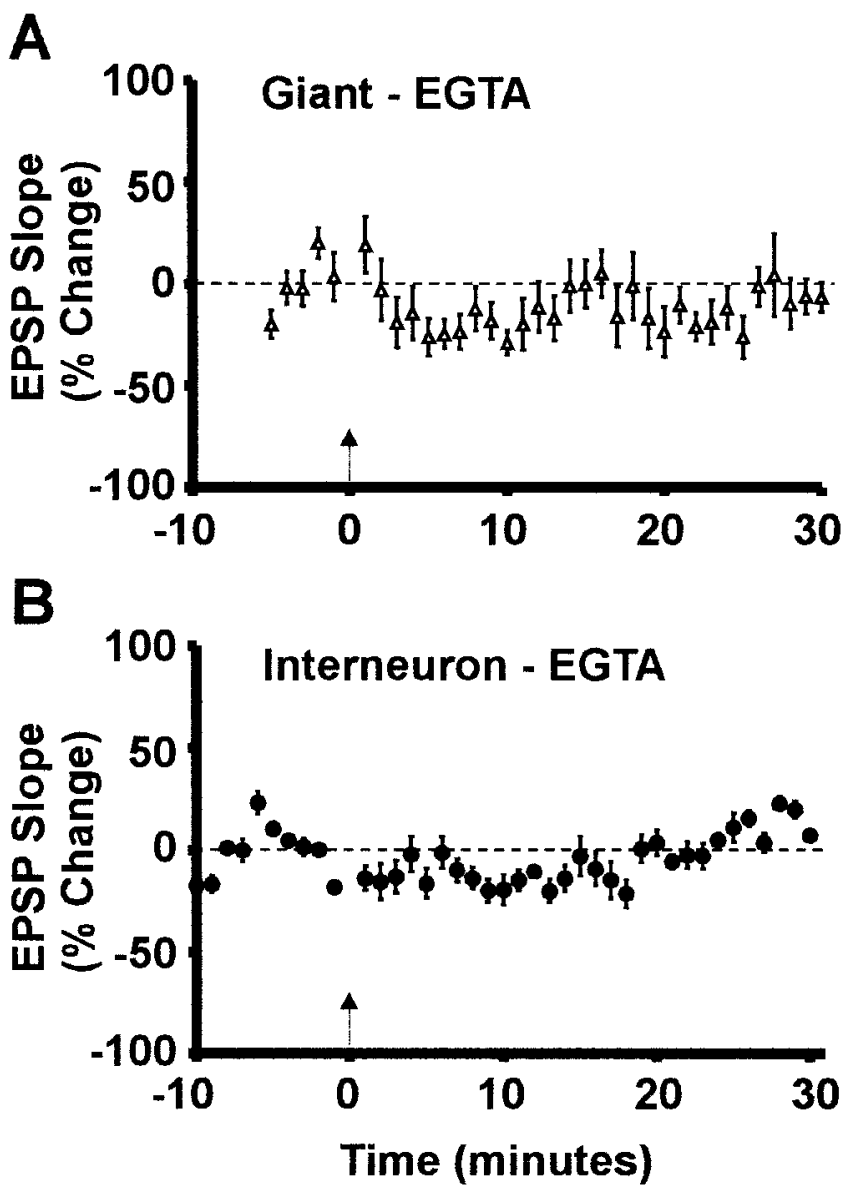

FIGURE 6. LTP induction in giant cells and interneurons was blocked by EGTA. A: Inclusion of the calcium chelator EGTA (10 $\mathrm{mM}$ ) in the whole-cell pipette blocked the LTP normally induced in giant cells by the $100-\mathrm{Hz}$ stimuli $(-12 \pm 18, \mathrm{n}=5, P>0.05)$. B: Ensemble averages of slope measurements obtained during similar experiments performed on interneurons $(7 \pm 3 \%, n=5, P>0.05)$, using $200-\mathrm{Hz}$ stimuli.

\section{Frequency-Specific LTP and LTD in Stratum Radiatum Giant Cells and Interneurons?}

The application of high-frequency conditioning stimuli served to further differentiate the two cell types. A significant degree of LTP was only produced in interneurons following the application a $200-\mathrm{Hz}$ stimulus, and not following $100-\mathrm{Hz}$ stimuli. A novel aspect of the LTP observed with the $200-\mathrm{Hz}$ stimulation was that it was induced at physiological temperatures, but not at room temperature. In contrast, LTP was not induced in giant cells with the $200-\mathrm{Hz}$ stimuli, but was observed following the application of tetanic stimulation at $100 \mathrm{~Hz}$.

Another difference in the two cell types was apparent following the administration of the $200-\mathrm{Hz}$ conditioning stimuli, while NMDAr were blocked with APV. Under these conditions, LTP was prevented in stratum radiatum interneurons, while a significant degree of LTD was induced in giant cells under NMDAr blockade. This difference suggests that $200-\mathrm{Hz}$ stimulation may simultaneously induce an NMDAr-dependent LTP and NMDArindependent LTD in giant cells. In contrast to interneurons, but

like CA1 pyramidal cells (Reymann et al., 1989; Grover and Teyler, 1990b), neither LTP nor LTD were induced when giant cells were administered the $100-\mathrm{Hz}$ stimuli in the presence of APV.

The LTP observed in giant cells and interneurons did not appear to be passively propagated from nearby pyramidal cells. The term "passive propagation" refers to LTP observed in the secondary components of EPSPs evoked in stratum oriens-alveus inhibitory neurons but mediated by pyramidal neurons (Maccaferri and McBain, 1995). The inclusion of the calcium chelator EGTA in the intracellular medium prevented the induction of monosynaptic LTP in both cell types. This manipulation suggests that the observed LTP is also calcium-dependent.


FIGURE 7. LTP of synaptic efficacy required NMDA-receptor activation in SR interneurons. A: Averaged waveforms prior to (i) and following (ii) tetanic stimulation in the presence of APV. B: Arrows indicate time points at which averaged waveforms were taken immediately prior to (1) and $30 \mathrm{~min}$ following (2) the application of the $200-\mathrm{Hz}$ stimuli. Individual responses were collected from a single interneuron in the presence of APV prior to and following the application of the 200-Hz stimuli. C: Averaged responses for all cells administered the tetanus in ACSF containing APV. LTP was blocked in all cells under these conditions. Scale bars $=2.5 \mathrm{mV}, 5 \mathrm{~ms}$. 


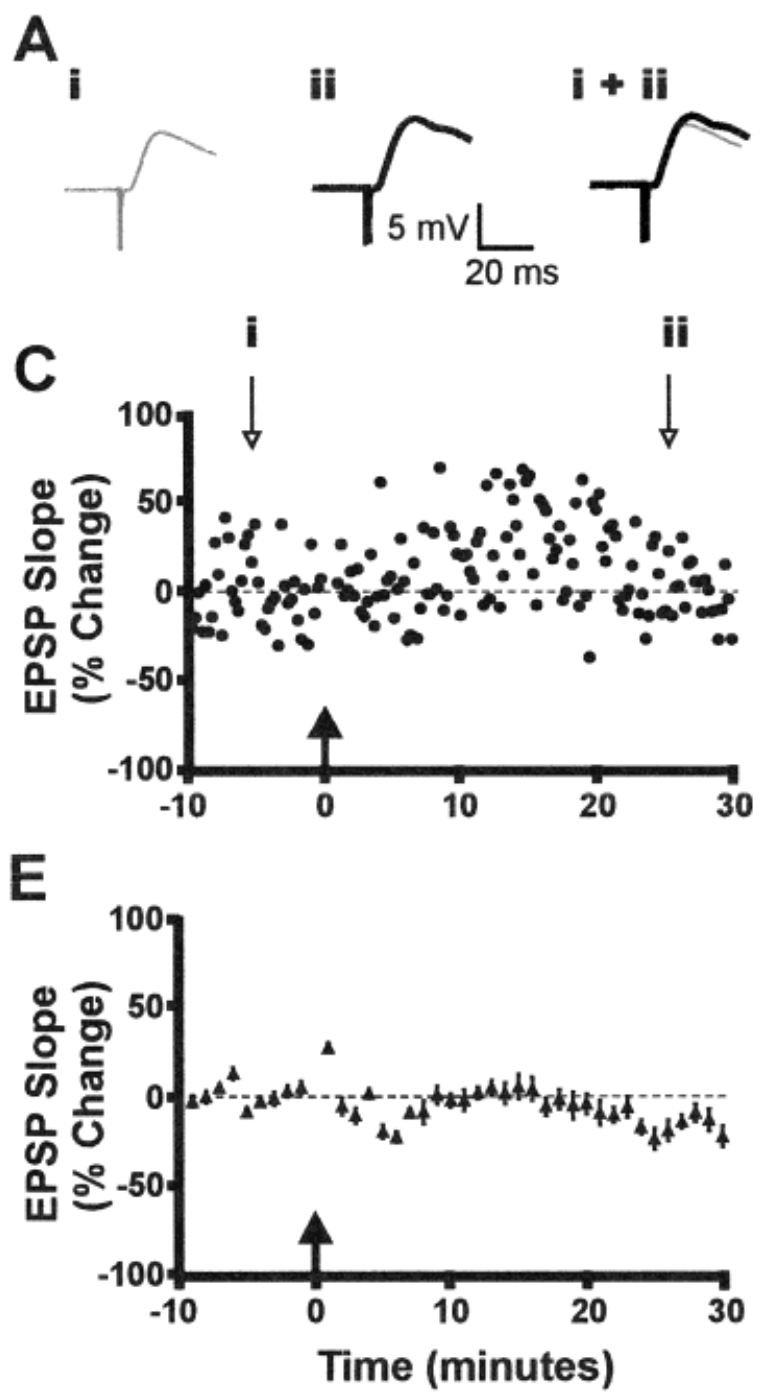

FIGURE 8. NMDAr antagonism in giant cells prevented the induction of LTP with $100-\mathrm{Hz}$ stimuli and revealed an NMDAr-independent LTD with $200-\mathrm{Hz}$ stimulation. A,B: Evoked responses prior to (i) and following (ii) the administration of $100-\mathrm{Hz}$ (A) and $200-\mathrm{Hz}$ (B) stimulation in the presence of APV $(50 \mu \mathrm{M})$. C: Individual responses recorded from a single neuron in the presence of APV. Application of the 100-Hz stimuli (solid arrow) failed to induce LTP in this

\section{Implications of Stratum Radiatum Neuronal LTP for Hippocampal Functioning}

Taken together, these findings provide further evidence that cells in the stratum radiatum region are capable of exhibiting synaptic plasticity. The ability of interneurons to exhibit long-term alterations in synaptic efficacy has a number of implications for the modulation of hippocampal circuits. Tsodyks et al. (1997) showed that increasing the strength of the inhibitory drive onto interneurons can increase network stability, and paradoxically increase the firing rate of interneurons. Since LTP of EPSPs and IPSPs may occur concurrently in a population of cells receiving a given input, Perez et al. (1999) suggested that LTP of interneurons could enhance the detection of populations of neurons that are being excited from those that are not. Interneuron LTP would result in
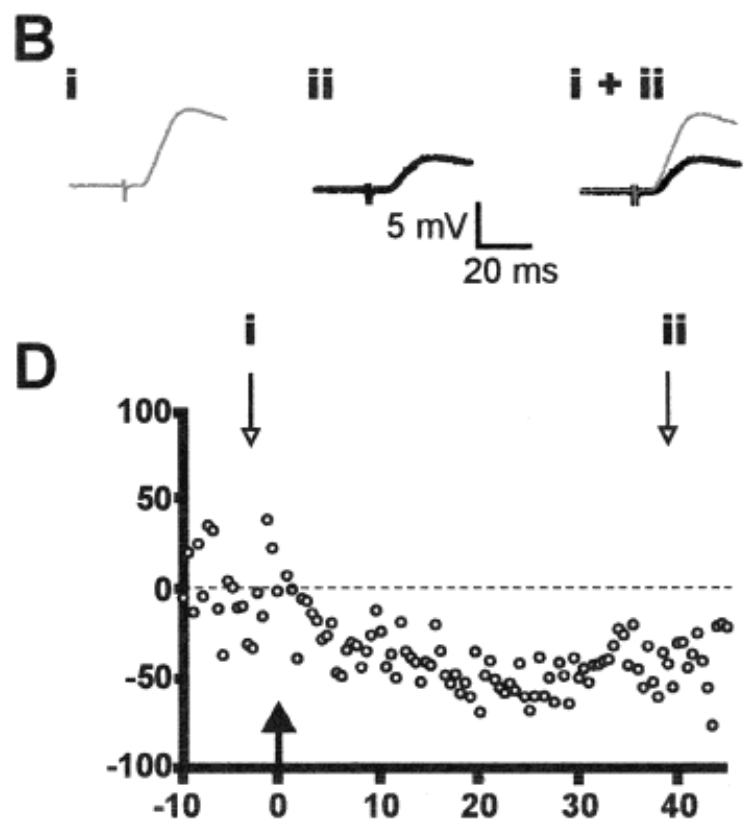

$\mathbf{F}$

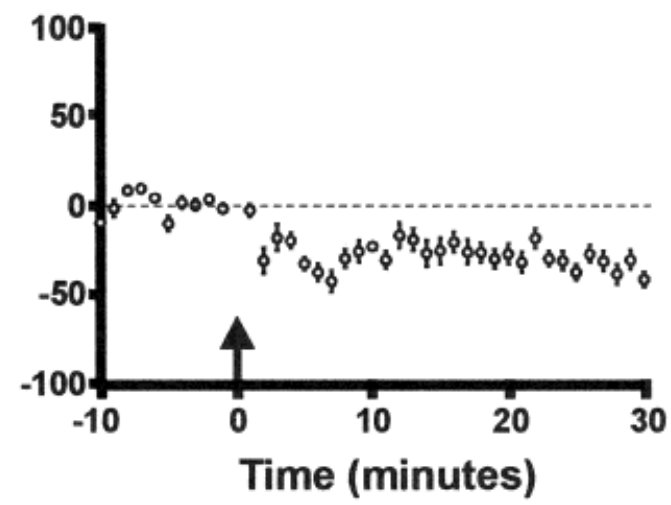

cell and in all cells examined. D: Single-evoked responses in a cell administered the $200-\mathrm{Hz}$ conditioning stimuli in the presence of APV show a pronounced and sustained depression. E: Averaged responses for all cells administered the $100-\mathrm{Hz}$ stimulation in the presence of APV. F: A pronounced depression is apparent in the averaged responses obtained from all cells administered the $200-\mathrm{Hz}$ stimulation in the presence of APV. Scale bars: $5 \mathrm{mV}, 20 \mathrm{~ms}$.

more inhibition, to downstream neurons, reducing their output. Giant cells may be strategically placed in the stratum radiatum to signal output regions that hippocampal pyramidal cell afferents are currently being inhibited. Future experiments will attempt to determine if these giant cells are the recipients of local circuit inhibitory connections as well.

\section{Acknowledgments}

The authors thank G. Buszaki, J. Kauer, J.-C. Lacaille, J. Magee, C. McBain, and C. Stevens for helpful comments during the course of these experiments. We also thank Lee Campbell for providing the data acquisition and analysis software and Bryan Nielsen for technical support. 


\section{REFERENCES}

Amaral DG, Witter MP. 1989. The three-dimensional organization of the hippocampal formation: a review of anatomical data. Neuroscience 31:571-591.

Bear MF, Malenka RC. 1994. Synaptic plasticity: LTP and LTD. Curr Opin Neurobiol 4:389-399.

Buhl EH, Cobb SR, Halasy K, Somogyi P. 1995. Properties of unitary IPSPs evoked by anatomically identified basket cells in the rat hippocampus. Eur J Neurosci 7:1989-2004.

Buhl EH, Szilagyi T, Halasy K, Somogyi P. 1996. Physiological properties of anatomically identified basket and bistratified cells in the CA1 area of the rat hippocampus in vitro. Hippocampus 6:294-305.

Buzsaki G, Eidelberg E. 1981. Commissural projection to the dentate gyrus of the rat: evidence for feed-forward inhibition. Brain Res 230: 346-350.

Christie BR, Kerr DS, Abraham WC. 1994. Flip side of synaptic plasticity: long-term depression mechanisms in the hippocampus. Hippocampus 4:127-135.

Christie BR, Magee J, Johnston D. 1996. The role of dendritic action potentials and $\mathrm{Ca} 2+$ influx in the induction of homosynaptic longterm depression in hippocampal CA1 pyramidal neurons. Learn Mem 3:160-169.

Cowan AI, Stricker C, Reece LJ, Redman SJ. 1998. Long-term plasticity at excitatory synapses on aspinous interneurons in area CA1 lacks synaptic specificity. J Neurophysiol 79:13-20.

Freund TF, Buzsaki G. 1996. Interneurons of the hippocampus. Hippocampus 6:345-474.

Grover LM. 1998. Evidence for postsynaptic induction and expression of NMDA receptor independent LTP. J Neurophysiol 79:1167-1182.

Grover LM, Teyler TJ. 1990a. Two components of long-term potentiation induced by different patterns of afferent activation. Nature 347: 477-479.

Grover LM, Teyler TJ. 1990b. Differential effects of NMDA receptor antagonist APV on tetanic stimulation induced and calcium induced potentiation. Neurosci Lett 113:309-314.

Grover LM, Teyler TJ. 1995. Different mechanisms may be required for maintenance of NMDA receptor dependent and independent forms of long-term potentiation. Synapse 19:121-133.

Gulyas AI, Toth CJ, McBain CJ, Freund TF. 1998. Stratum radiatum giant cells: a type of principal cell in the rat hippocampus. Eur J Neurosci 10:3813-3822.

Hinds HL, Tonegawa S, Malinow R. 1998. CA1 long-term potentiation is diminished but present in hippocampal slices from alpha-CaMKII mutant mice. Learn Mem 5(4-5):344-354.

Lacaille JC, Schwartzkroin PA. 1988. Stratum lacunosum-moleculare interneurons of hippocampal CA1 region. I. Intracellular response characteristics, synaptic responses, and morphology. J Neurosci 8:14001410.

Lacaille J-C, Kunkel DD, Schwartzkroin PA. 1989. Electrophysiological and morphological characterization of hippocampal interneurons. In: Chan-Palay V, Kohler C, editors. The hippocampus: new vistas. New York: Alan R. Liss. p 287-305.

Larkman AU, Jack JJ. 1995. Synaptic plasticity: hippocampal LTP. Curr Opin Neurobiol 5:324-334.

Lynch G, Larson J, Kelso S, Barrionuevo G, Schottler F. 1983. Intracellular injections of EGTA block induction of hippocampal long-term potentiation. Nature 305:719-721.

Maccaferri G, McBain CJ. 1995. Passive propagation of LTD to stratum oriens-alveus inhibitory neurons modulates the temporoammonic input to the hippocampal CA1 region. Neuron 15:137-145.
Maccaferri G, McBain CJ. 1996. Long-term potentiation in distinct subtypes of hippocampal nonpyramidal neurons. J Neurosci 16:53345343.

Malenka RC, Kauer JA, Zucker RS, Nicoll RA. 1988. Postsynaptic calcium is sufficient for potentiation of hippocampal synaptic transmission. Science 242:81-84.

McBain CJ, Dingledine R. 1993. Heterogeneity of synaptic glutamate receptors on CA3 stratum radiatum interneurones of rat hippocampus. J Physiol (Lond) 462:373-392.

McBain CJ, Freund TF, Mody I. 1999. Glutamatergic synapses onto hippocampal interneurons: precision timing without lasting plasticity. Trends Neurosci 22:228-235.

McMahon LL, Kauer JA. 1997. Hippocampal interneurons express a novel form of synaptic plasticity. Neuron 18:295-305.

Ouardouz M, Lacaille J-C. 1995. Mechanisms of selective long-term potentiation of excitatory synapses in stratum oriens/alveus interneurons in rat hippocampal slices. J Neurophysiol 73:810-819.

Parra P, Gulyas AI, Miles R. 1998. How many subtypes of inhibitory cells in the hippocampus? Neuron 20:983-993.

Perez Y, Chapman CA, Woodhall G, Robitaille R, Lacaille JC. 1999. Differential induction of long-lasting potentiation of inhibitory postsynaptic potentials by theta patterned stimulation versus $100-\mathrm{Hz}$ tetanization in hippocampal pyramidal cells in vitro. Neuroscience 90:747-757.

Reymann KG, Matthies HK, Schulzeck K, Matthies H. 1989. N-methyl$\mathrm{D}$-aspartate receptor activation is required for the induction of both early and late phases of long-term potentiation in rat hippocampal slices. Neurosci Lett 96:96-101.

Schwartzkroin PA, Mathers LH. 1978. Physiological and morphological identification of a nonpyramidal hippocampal cell type. Brain Res 157:1-10.

Shankar S, Teyler TJ, Robbins N. 1998. Aging differentially alters forms of long-term potentiation in rat hippocampal area CA1. J Neurophysiol 79:334-341.

Sik A, Hajos N, Gulacsi A, Mody I, Freund TF. 1998. The absence of a major $\mathrm{Ca} 2+$ signaling pathway in GABAergic neurons of the hippocampus. Proc Natl Acad Sci USA 95:3245-3250.

Stelzer A, Simon G, Kovacs G, Rai R. 1994. Synaptic disinhibition during maintenance of long-term potentiation in the CA1 hippocampal subfield. Proc Natl Acad Sci USA 91:3058-3062.

Taube JS, Schwartzkroin PA. 1987. Intracellular recording from hippocampal CA1 interneurons before and after development of longterm potentiation. Brain Res 419:32-38.

Tsodyks MV, Skaggs WE, Sejnowski TJ, McNaughton BL. 1997. Paradoxical effects of external modulation of inhibitory interneurons. J Neurosci 17:4382-4388.

Valtschanoff JG, Weinberg RJ, Kharazia VN, Nakane M, Schmidt HH. 1993. Neurons in rat hippocampus that synthesize nitric oxide. J Comp Neurol 331:111-121.

van Groen T, Wyss JM. 1990. Extrinsic projections from area CA1 of the rat hippocampus: olfactory, cortical, subcortical, and bilateral hippocampal formation projections. J Comp Neurol 302:515-528.

Wang JH, Kelly PT. 1996. The balance between postsynaptic Ca(2+)dependent protein kinase and phosphatase activities controlling synaptic strength. Learn Mem 3:170-181.

Williams S, Samulack DD, Beaulieu C, LaCaille JC. 1994. Membrane properties and synaptic responses of interneurons located near the stratum lacunosum-moleculare/radiatum border of area CA1 in whole-cell recordings from rat hippocampal slices. J Neurophysiol 71:2217-2235.

Yeckel MF, Kapur A, Johnston D. 1999. Multiple forms of LTP in hippocampal CA3 neurons use a common postsynaptic mechanism. Nat Neurosci 2:625-633. 